\title{
Gravity Models in R
}

\author{
Anna-Lena Wölwer \\ Trier University
}

\author{
Jan Pablo Burgard \\ Trier University
}

\author{
Martin Breßlein \\ Bundesnetzagentur
}

\begin{abstract}
Gravity models are used to explain bilateral flows related to the sizes of bilateral partners, a measure of distance between them and other influences on interaction costs. The underlying idea is rather simple. The greater the masses of two bodies and the smaller the distance between them, the stronger their attraction. Even though their basic idea is rather simple, gravity models can become complex regarding the choice of models and estimation methods. As especially for gravity beginners it is difficult to get an overview of the different methods and implement them in $\mathrm{R}$, the package gravity provides a wrapper of different standard estimation methods. By considering the descriptions and codes of these methods, users can get a comprehensive and application-oriented access, see which method may be suitable for certain research questions or types of data, and extend the code available for their specific research projects.
\end{abstract}

Gravitationsmodelle werden verwendet, um bilaterale Ströme zu erklären. Dabei werden sowohl Größen und Distanz der jeweiligen Partner als auch weitere Einflussfaktoren zur Erklärung herangezogen. Die zugrundeliegende Idee dieser Modelle beruht auf dem Gravitationsprinzip. Je schwerer zwei Körper und je kleiner deren Distanz zueinander, desto stärker ist ihre gegenseitige Anziehungskraft. Auch wenn die zugrundeliegende Idee von Gravitationsmodellen zunächst intuitiv erscheint, kann deren Schätzung je nach theoretischem Hintergrund und verwendeter Schätzmethode komplex werden. Da es insbesondere für Nutzer, die sich neu mit Gravitationsmodellen beschäftigen, schwierig ist einen Überblick über die verschiedenen Methoden zu erhalten und diese direkt selbst anzuwenden, bietet das Paket gravity einen Wrapper verschiedenster Standard-Schätzmethoden für Gravitationsmodelle. Durch die Beschreibung sowie die direkte Anwendbar- und Vergleichbarkeit dieser anhand des beigefügten Datensatzes können Anwender einen anwendungsorientierten Überblick über die Methoden, ihre Anwendbarkeit für verschiedene Forschungsfragen und Voraussetzungen an Daten gewinnen und den zugrundeliegenden Code für ihre eigenen Forschungsfragen erweitern.

Keywords: gravity model, international trade, migration, $\mathrm{R}$.

\section{Introduction}

Gravity models in their naive form trace back to the work of Tinbergen (1962) and Ravenstein (1889). They owe their popularity to high explanatory power and relatively robust results across many datasets and different scientific works (Anderson 2011). As Baier and Bergstrand (2010) argue, the topics addressed by gravity models, such as international trade, migration 
flows or foreign direct investment, are of high political relevance. The most widespread application, however, is for international trade flows (Möhlmann, Ederveen, de Groot, and Linders 2010). In consequence of a sound theoretical basis (for trade mainly thanks to the contribution of Anderson and van Wincoop (2003)) the popularity of gravity models rose within the last twenty years and they can nowadays be found in many variations and applications.

Even though the basic idea of gravity models is rather simple, they can become complex when it comes to the choice of models or estimation methods. For the choice of a specific gravity model and its theoretical background, see the literature referred to in this article. Some estimation methods can be burdensome to understand and program for researchers starting to work with gravity models. In order to provide users of gravity models and $\mathrm{R}$ with a wrapper of some of the most common used methods for estimating gravity models, we implemented the package gravity. The functions included in the package are listed in Table 1.

Table 1: Functions of the package gravity

\begin{tabular}{lll}
\hline Algorithm & Function & Section \\
\hline Ordinary Least Squares & OLS() & 4.2 \\
Fixed Effects & Fixed_Effects() & 4.3 \\
Double Demeaning & DDM() & 4.4 \\
Bonus vetus OLS with simple averages & BVU() & 4.5 \\
Bonus vetus OLS with GDP weights & BVW() & 4.5 \\
Structural Iterated Least Squares & SILS() & 4.6 \\
Tetrads & Tetrads() & 4.7 \\
Tobit & Tobit() & 4.8 \\
ET-Tobit, Eaton and Tamura (1994) & ET_Tobit() & 4.9 \\
EK-Tobit, Eaton and Kortum (2001) & EK_Tobit() & 4.10 \\
Poisson Pseudo Maximum Likelihood & PPML() & 4.11 \\
Gamma Pseudo Maximum Likelihood & GPML() & 4.12 \\
Negative Binomial Pseudo Maximum Likelihood & NBPML() & 4.13 \\
Nonlinear Least Squares & NLS() & 4.14 \\
\hline
\end{tabular}

They can be subdivided into two types of estimation methods: those estimating gravity models in their log-log form, such as Ordinary Least Squares (OLS), Fixed Effects, Double Demeaning (DDM), Bonus vetus OLS with simple averages (BVU) and with GDP-weights (BVW), Structural Iterated Least Squares (SILS), Tetrads, and different Tobit style methods (Tobit, ET-Tobit, and EK-Tobit). These methods are partly complex to understand and program and thus a comparison of them is not straightforward. Therefore the package aims at easing an overview of the different methods combined with a direct application. Furthermore, except for the Tobit style methods, these methods are not capable of handling zero values in the dependent variable just like that. A second type of estimation methods estimates gravity models in their multiplicative form via generalized linear models with a log-link using different distribution families. These methods are relatively easy to compute and added for completeness. They contain the methods Poisson Pseudo Maximum Likelihood (PPML), Gamma Pseudo Maximum Likelihood (GPML), Negative Binomial Pseudo Maximum Likelihood (NBPML), and Nonlinear Least Squares (NLS). As they estimate the gravity equation in its multiplicative form, all of them but GPML are capable of utilizing datasets with zero values in the dependent variable. The functions of the package all differ with respect to their underlying assumptions and prerequisites concerning data, their ability to handle missing values, as well as their capability of including different effects in the estimation. By considering the descriptions of the estimation methods, users can see which method and data may be suited for certain research questions. In order to have a straightforward application of all methods, the package comes with two example datasets (Gravity_no_zeros and Gravity_zeros, see Section 
3). Examples utilizing these datasets are included in the descriptions of the methods. The user can for example see how the results of the estimation methods may differ even though they are applied to the same dataset. As the range of gravity models and their suitable estimation methods is huge and specific to data and research question at hand, the functions are kept simple such that researchers can get familiar with them and utilize them as a starting point of their research.

In the following we describe gravity models in general as well as the example datasets and present the different estimation methods in the $\mathrm{R}$ package gravity.

\section{Gravity models}

Gravity models in their traditional form are inspired by Newton's (1729) law of gravitation:

$$
F_{i j}=G \frac{M_{i} M_{j}}{D_{i j}^{2}} .
$$

The force $F$ between two bodies $i$ and $j$ with $i \neq j$ is proportional to the masses $M$ of these bodies and inversely proportional to the square of their geographical distance $D . G$ is a constant and as such of no major concern.

The underlying idea of a traditional gravity model, shown for international trade, is equally simple (based on Anderson 2011):

$$
X_{i j}=G \frac{Y_{i}^{\beta_{1}} Y_{j}^{\beta_{2}}}{D_{i j}^{\beta_{3}}} .
$$

Let interaction in form of trade flows be $X$ and let $Y_{i}$ and $Y_{j}$ be the masses of the exporting and importing country, usually approximated by a measure of GDP. Following equation (2), the greater the GDPs of two countries and the smaller the geographical distance $D_{i j}$ between them, the more they trade with each other. Similar to Newton's model in equation (1), the coefficients for countries' incomes were often found to be close to unity (see for example Head and Mayer 2014). As unitary income elasticities are in line with theoretical foundations like Anderson and van Wincoop (2003), it is therefore sometimes assumed that the income elasticities are equal to unity (see for example Anderson 2010), meaning $\beta_{1}=\beta_{2}=1$. Besides these basic parts of a gravity model all other variables determining the trade volume or interaction between two countries can be added to the model as proxies for transaction costs. Tinbergen (1962) mentions trade agreements, historical backgrounds, political situations, common languages, religion or cultural similarities between bilateral partners as potential dummy variables. We can define a term $t$ in equation (3) catching the transaction costs between two countries. Dummy variables can be added in $t$, e.g. contig for common borders or rta for regional trade agreements.

$$
t_{i j}=D_{i j} e^{\text {contig }_{i j}} e^{r t a_{i j}}=\exp \left(\log D_{i j}+\text { contig }_{i j}+r t a_{i j}\right)
$$

After estimating the coefficients of the transaction costs, one can for example compare theoretical and real trade flows and thereby reveal trade barriers. Gravity equations can be easily transformed from a multiplicative to an additive form by taking the logarithm. The gravity model in equation (2) added by the transaction costs in equation (3) can therefore be written in an additive form as:

$$
\log X_{i j}=\beta_{0} \log G+\beta_{1} \log Y_{i}+\beta_{2} \log Y_{j}+\beta_{3} \log D_{i j}+\beta_{4} \text { contig }_{i j}+\beta_{5} r t a_{i j} .
$$

A gravity equation in its additive form can be estimated by standard estimation methods such as OLS. For inference problems arising when estimating a logged variable, see Manning 
(1998). He presents potential retransformations when a variable of interest is estimated on its logged-scale even though the real interest is in its unlogged-scale with focus on the case of heteroscedasticity.

Baier and Bergstrand (2010) state that the main disadvantage of traditional gravity models, such as (2) and (4), is the negation of the rest of the world. Baldwin (2007) calls this negation the gold medal mistake. The traditional model only captures transaction costs between bilateral partners and ignores transaction costs to the rest of the world and can therefore lead to implausible results and does not allow for comparative statics (see Anderson and van Wincoop (2003) for further information). In order to incorporate the effects other countries can have on the trade volume of bilateral partners, a measure of multilateral resistance (MR) is usually included in gravity models.

Anderson (1979) includes the rest of the world in the theoretical basis of gravity models to allow the exports from $i$ to $j$ to be influenced by other demands for the goods of $i$ and other suppliers for the goods of $j$. The term MR is used in later work of Anderson and van Wincoop (2003). They describe how the trade volume between two countries can decrease as a consequence of changing relative trade barriers of the two countries to their other trading partners. Anderson and van Wincoop (2003) define MR as the average trade barrier for the importing and exporting country. They furthermore find that small countries, which trade much with the rest of the world, react stronger to changes in trade barriers than bigger countries.

For the theoretical basis of a gravity model including MR terms, also called structural gravity, see Anderson and van Wincoop (2003) and Anderson (1979). Anderson and van Wincoop (2003) set up a gravity model with MR terms as:

$$
X_{i j}=\frac{Y_{i} Y_{j}}{Y} \frac{t_{i j}^{1-\sigma}}{P_{j}^{1-\sigma} \Pi_{i}^{1-\sigma}}
$$

with

$$
\Pi_{i}^{1-\sigma}=\sum_{j} \frac{t_{i j}^{1-\sigma}}{P_{j}^{1-\sigma}} \frac{Y_{j}}{Y}
$$

and

$$
P_{j}^{1-\sigma}=\sum_{i} \frac{t_{i j}^{1-\sigma}}{\Pi_{i}^{1-\sigma}} \frac{Y_{i}}{Y} .
$$

Just like in the traditional gravity models, the exports $X_{i j}$ from $i$ to $j$ are determined by the supply factors in $i, Y_{i}$, the demand factors in $j, Y_{j}$, as well as the transaction costs $t_{i j}$ from $i$ to $j$. Next to information on bilateral partners $i$ and $j$, information on the rest of the world is included in the gravity model (5). $Y$ with $Y=\sum_{i} Y_{i}=\sum_{j} Y_{j}$ represents the worldwide sum of incomes. $\sigma$ represents the elasticity of substitution between all goods with $\sigma>1$ in order to account for the preference for a variation of goods. The MR terms are included via the terms $P$, inward MR, and $\Pi$, outward MR. The outward MR $\Pi_{i}$ is a function of the transaction costs of $i$ to all trade partners $j$ and their demand, $P_{j}$ vice versa. The MR terms (6) and (7) dependent on each other.

Under the assumption of symmetrical trade costs, $t_{i j}=t_{j i}$, and thereby $P_{i}=\Pi_{i}$ one obtains a symmetric gravity model (Anderson and van Wincoop 2003):

$$
X_{i j}=\frac{Y_{i} Y_{j}}{Y} \frac{t_{i j}^{1-\sigma}}{P_{j}^{1-\sigma} P_{i}^{1-\sigma}} .
$$


Due to the MR terms, the estimation of structural gravity models is more complex. See for example Head and Mayer (2014) or Gómez-Herrera (2013) for information on the development of gravity models for trade data.

Apart from the application to international trade, gravity models can be used for many purposes such as migration (see for example Orlova and Jost 2006), traffic (see for example Wang 2011), Foreign Direct Investment (FDI) (see for example Leibrecht and Riedl 2014), or the estimation of political action such as trade unions (see for example Martínez-Zarzoso, Nowak-Lehmann D., and Vollmer 2007). Head and Mayer (2014) give an overview about these different applications. Anderson (1979) describes gravity models as flexible concerning data used and Bergeijk and Brakman (2010) highlight the advantages of the possibility to use different levels of aggregation.

Datasets for gravity models often contain a huge amount of trade flows equal to zero. In data for international trade flows, these zeros can occur if two countries do not trade with each other, the trade flow between countries is so small that it rounds to zero or the trade flows were not observed. As Metulini, Patuelli, and Griffith (2016) highlight, it is nowadays - especially considering sector disaggregated flows - widely recognized that the level of trade between two entities can in fact be zero. The econometric models behind the gravity equation used should therefore reflect the possibility of zero trade flows (see e.g. the discussion about zeros in Anderson (2010)). Next to the theoretical background, also the estimation method used should be capable of handling zero value. Estimation methods utilizing gravity models in their logged form, such as OLS, Fixed Effects, DDM, BVU, BVW, SILS, and Tetrads cannot handle zero trade flows without further ado as the log of zero is not defined. In addition, also GPML is not capable of handling zeros flows as such. One simple solution would be to add a small constant to the flow values such that the zeros disappear and all flows can be logged. This, however, is criticized by many authors (see e.g. the discussion by Head and Mayer (2014)) as not only the theoretical foundation of this transformation is missing, but results can be highly volatile with respect to the magnitude of the constant. In order to see how volatile the estimation outcomes are with respect to the chosen constant, a possibility would be to estimate a chosen model with differently scaled constants and see whether the results change much by choice of the constant.

Another type of methods estimating the gravity equation in its additive form, but explicitly designed for a handling flows equal to zero are Tobit style models. Tobit models are used for censored data, where instead of the observed data a latent variable is modeled. The function Tobit adds a constant (default constant is 1) to the dependent variable and utilizes a Tobit regression with the censoring value equal to $\log$ (constant) for the logged dependent variable, which in case of constant $=1$ is 0 . For the threshold Tobit model by Eaton and Tamura (1994), called ET-Tobit, on the other hand, this constant, or threshold, is estimated from the data. For the estimation of the threshold we follow Carson and Sun (2007), who show that taking the minimum positive flow value as the threshold is super-consistent and that using this threshold estimate ensures that the parameter maximum likelihood estimates are asymptotically normal with the asymptotic variance identical to the variance achieved when the threshold is known. In addition, there is the Eaton and Kortum (2001) Tobit model, called EK-Tobit. In EK-Tobit, all observations of the dependent variable are redefined as intervals. The positive observations have both interval bounds equal to their original value. For zero flows the interval is left open. The right border of the interval is set to the log of the minimum trade flow of the respective importing country. Then, an interval regression is applied. For a short comparison of the three methods, see e.g. Head and Mayer (2014).

The estimation methods estimating the gravity equation in its multiplicative form (except for GPML), i.e. PPML, NBPML, and NLS, on the other hand, can utilize zero trade values. Nevertheless, these estimation methods can often not explain the great amount of zeros in data, but only part of it. Possible solutions for both estimation methods utilizing the multiplicative or logged form of the gravity equation when zero trade flows are frequent, e.g. censored, truncated, and zero-inflated methods, are proposed by many authors. See e.g. Mar- 
tin and Pham (2015), Burger, Van Oort, and Linders (2009), Kareem, Martinez-Zarzoso, and Brümmer (2016), Anderson (2011), Gómez-Herrera (2013), Linders and De Groot (2006), and Head and Mayer (2014) for further information.

We refer the user to the Gravity Cookbook website ${ }^{1}$ for more information on gravity models in general. Head and Mayer (2014) provide a comprehensive and accessible overview of the theoretical and empirical development of the gravity literature as well as the use of gravity models and the various estimation methods, especially their merits and potential problems regarding applicability as well as different gravity datasets.

\section{Example datasets}

In order to illustrate the different estimation methods, the package gravity includes two dataset called Gravity_zeros and Gravity_no_zeros. These datasets on international trade are obtained by editing the gravity dataset "col_regfile09.dta" available at the Gravity Cookbook website ${ }^{2}$. In order to have dataset suited for most functions, the datasets are limited to cross-sectional data. All incomplete rows and observations with missing trade flows were excluded from the dataset. In addition, for Gravity_no_zeros observations with trade flows equal to zero were deleted.

The dataset was downloaded and transformed in the following way:

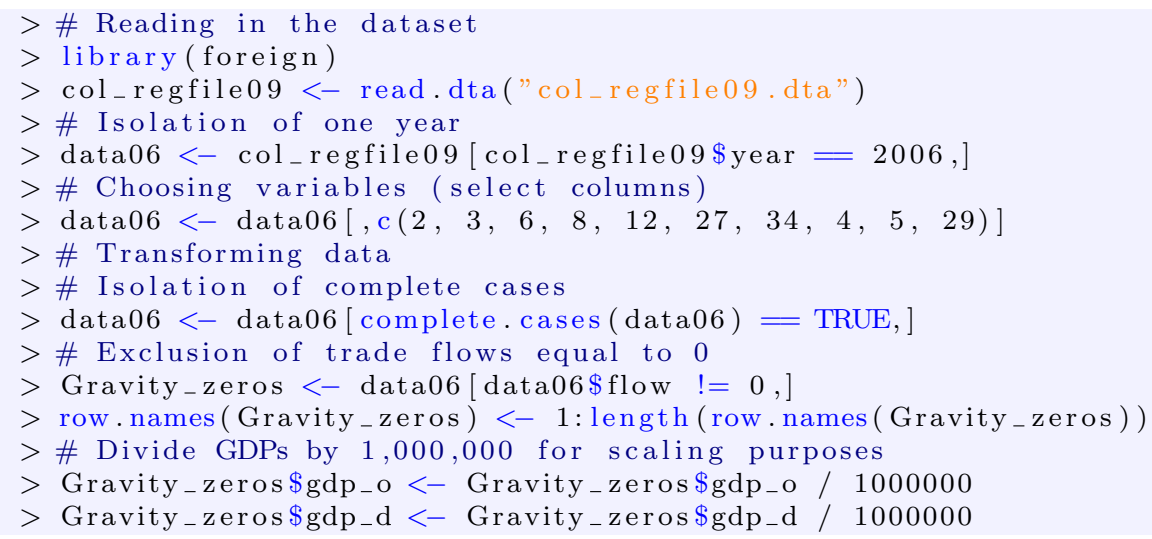

For Gravity_no_zeros the following line is added

$>$ \# Exclusion of trade flows equal to 0

$>$ Gravity_no_zeros $<-$ data06[data06\$flow $!=0$, ]

The resulting datasets consist of 22.588 (Gravity_zeros) and 17.088 (Gravity_no_zeros) observations respectively. Both include the following variables, exemplary shown for Gravity_zeros:

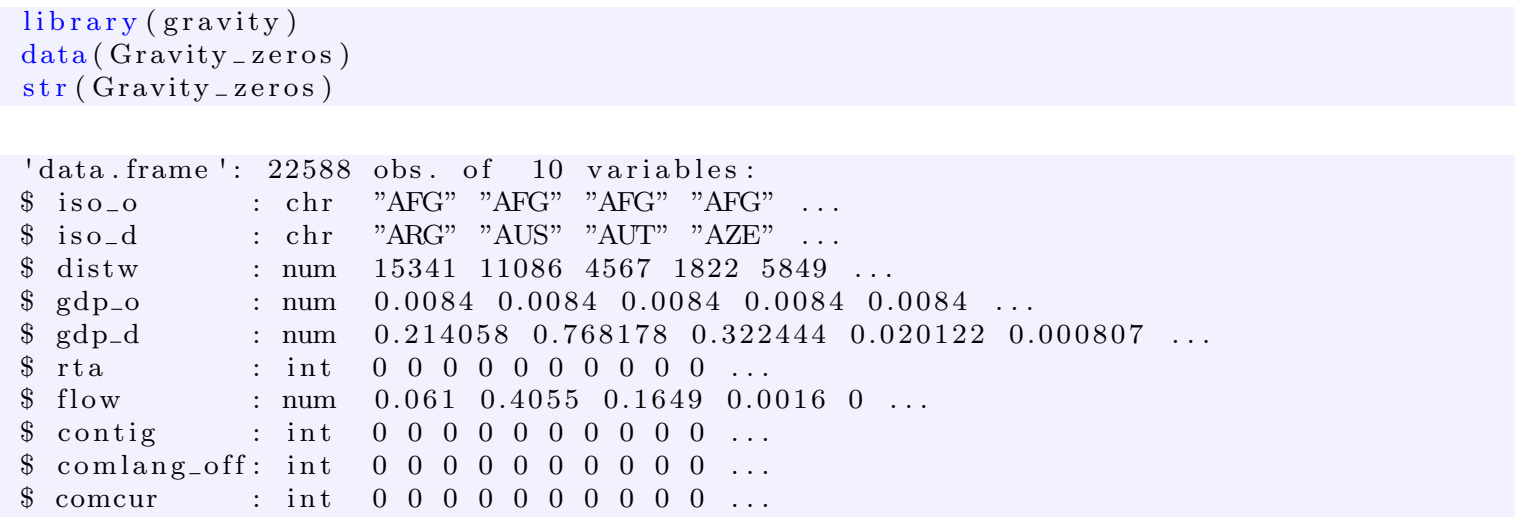

The descriptions of the variables are provided in Table 2 .

\footnotetext{
${ }^{1}$ https://sites.google.com/site/hiegravity/

${ }^{2}$ http://econ.sciences-po.fr/sites/default/files/file/tmayer/data/col_regfile09.zip
} 
Table 2: Description of the variables in the Gravity dataset

\begin{tabular}{ll}
\hline name & description \\
\hline iso_o & ISO-Code of country of origin \\
iso_d & ISO-Code of country of destination \\
distw & weighted distance (see Mayer and Zignago 2011) \\
gdp_o & GDP of country of origin in trillion dollars \\
gdp_d & GDP of country of destination in trillion dollars \\
rta & dummy for a regional trade agreement \\
flow & trade flow in million dollars \\
contig & dummy for regional contiguity \\
comlang_off & dummy for a common official language \\
comcur & dummy for a common currency \\
\hline
\end{tabular}

\section{Gravity functions}

\subsection{Structure of the functions}

On the Gravity Cookbook website ${ }^{3}$ Keith Head and Thierry Mayer provide Stata code the most common estimation methods for gravity models. Where possible the functions were designed and tested to lead similar results when choosing the option of robust variance estimation (default). Compared to the Stata code available, the functions presented in this package provide users with more flexibility regarding the type of estimation (robust or not robust), the number and type of independent variables as well as the possible data and are directly applicable to the dataset included in the package.

As the functions were - where possible - tested to lead the same results as the provided Stata code for cross-sectional data, it is up to the user to ensure that the functions can be applied to panel data. In order to be comparable, the functions of the package include distance as an independent variable. If panel data are used, time-invariant effects, such as geographical distance, may have to be excluded. The most common challenges when using panel data with gravity models arise because of missing trade flows, unbalanced panels, and computational difficulties. For a comprehensive overview see Egger and Pfaffermayr (2003), Gómez-Herrera (2013) and Head, Mayer, and Ries (2010) as well as the references therein. Egger and Pfaffermayr (2003) provide some comparison of cross-sectional and panel models and show differences when using different variables. Depending on the panel dataset and the variables - specifically the type of fixed or random effects - included in the model, it may easily occur that the model is not computable. Also, note that by including bilateral fixed effects such as country-pair effects, the coefficients of time-invariant observables such as distance can no longer be estimated. Depending on the specific model, the code of the respective function may has to be changed by hand in order to exclude the distance variable from the estimation. When using panel data, the parameter and variance estimation of the models may have to be adjusted accordingly. To our knowledge at the moment, there is no explicit literature covering the estimation of a gravity equation by Double Demeaning (DDM), Structural Iterated Least Squares (SILS) or Bonus vetus OLS (BVU, BVW) using panel data. Therefore, we do not recommend to apply these methods in this case.

The functions in gravity all estimate gravity models, but they do so in different ways. They differ in whether they estimate gravity equations in their additive or multiplicative form, their requirements with respect to data, their handling of Multilateral Resistance (MR) terms as well as their possibilities concerning the inclusion of unilateral independent variables, such as GDPs or population sizes. Therefore, they usually lead to different estimation results.

To execute the functions in gravity, a square gravity dataset with all pairs of countries, ISO-

\footnotetext{
${ }^{3}$ https://sites.google.com/site/hiegravity/
} 
codes for the country of origin and destination, a measure of distance between the bilateral partners as well as all information that should be considered as dependent and independent variables is needed. Missing bilateral flows as well as incomplete rows should be excluded from the dataset. Depending on the method used, zero values in the dependent variable may have to be excluded.

The functions listed in Table 1 generally have the same structure. Table 3 lists variables common to all functions. Additional arguments for specific functions are listed in the section describing the respective function.

Table 3: Function variables

\begin{tabular}{ll}
\hline Variable & Usage \\
\hline y & name (type: character) of the dependent variable in the dataset data, \\
& e.g. trade flows. It should not yet be logged. For functions estimating \\
gravity equations in their additive form, y is logged automatically. \\
name (type: character) of the distance variable in the dataset data con- \\
taining a measure of distance between all pairs of bilateral partners. It \\
should not yet be logged. For functions estimating gravity equations in \\
their additive form dist is logged automatically. \\
vector of names (type: character) of bilateral variables in the dataset \\
data that should be taken as the independent variables in the estimation. \\
If an independent variable is a dummy variable, it should be of type \\
numeric in the dataset. If an independent variable is defined as a ratio, \\
it should be logged. \\
variable name (type: character) of the income of the country of origin \\
in the dataset data. \\
variable name (type: character) of the income of the country of destina- \\
tion in the dataset data. \\
robust (type: logic) determines whether a robust variance-covariance \\
matrix should be used for the standard errors. The default is set to \\
inc_d \\
TRUE. If set TRUE the estimation results are similar to the Stata results \\
for robust estimation. \\
name of the dataset to be used (type: character). To estimate gravity \\
equations, a square gravity dataset including bilateral flows defined by \\
the argument y, ISO-codes (called iso_o for the country of origin and \\
iso_d for the destination country), a distance measure defined by the \\
argument dist and other potential influences given as a vector in $x$ are \\
required. All dummy variables should be of type numeric. Missing trade \\
flows as well as incomplete rows should be excluded from the dataset. \\
Note that for some functions, zero flow values have to be excluded or \\
transformed, see the descriptions of the respective functions. When \\
using panel data, a variable for the time may be included in the dataset. \\
Note that the variable for the time dimension should be of type: factor. \\
data
\end{tabular}

In order to show users how the functions can be applied, each description of a function comes with an example of how to apply it using an example dataset in gravity including the resulting output. As our main aim is to provide R users with a wrapper of different estimation methods for gravity models and we would like to illustrate all functions using simple examples, the variables chosen to be included in $\mathrm{x}$ as well as the choice of setting vce_robust to TRUE or FALSE are arbitrary. In order to execute the functions, the package and the example datasets have to be called first: 


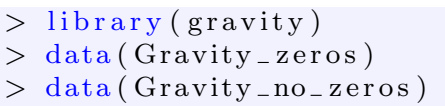

\subsection{OLS}

The function OLS estimates gravity models in their traditional form via Ordinary Least Squares using the $1 \mathrm{~m}$ function implemented in R. MR terms are not considered by this function; see the gold medal mistake described in Baldwin (2007). As OLS is limited to (log-)linear relationships, gravity equations are estimated in their additive form. The user has to pay attention that no zero trade flows are allowed in the dataset. Simple OLS is implemented in gravity as it is the traditional way of estimating gravity equations and was used by e.g. Tinbergen (1962). Baier and Bergstrand (2010) argue that the possibility to estimate gravity equations by simple OLS was a major contribution to the popularity of gravity models. As the estimated coefficients for the country's incomes were often found to be close to unity (see for example Head and Mayer 2014) and unitary income elasticities are in line with theoretical foundations like Anderson and van Wincoop (2003), it is sometimes assumed that the income elasticities are equal to unity (see for example Anderson 2010). In order to allow for the estimation with and without the assumption of unitary income elasticities, the option uie is built into the function OLS with the default set to FALSE; see Table 4.

Table 4: Additional variables for OLS

\begin{tabular}{ll}
\hline Variable & Usage \\
\hline uie & Unitary Income Elasticities (type: logic) determines whether the pa- \\
& rameters are to be estimated assuming unitary income elasticities. The \\
& default value is set to FALSE. If uie is set TRUE, the flows in the depen- \\
& dent variable y are divided by the product of the country-pairs' incomes \\
& before the estimation. If uie is set to FALSE, the income variables are \\
& logged and taken as independent variables in the estimation. The vari- \\
& able names for the incomes should be inserted into inc_o for the country \\
& of origin and into inc_d for the destination country.
\end{tabular}

An example of how to apply the function OLS to an example dataset in gravity and the resulting output is shown in the following:

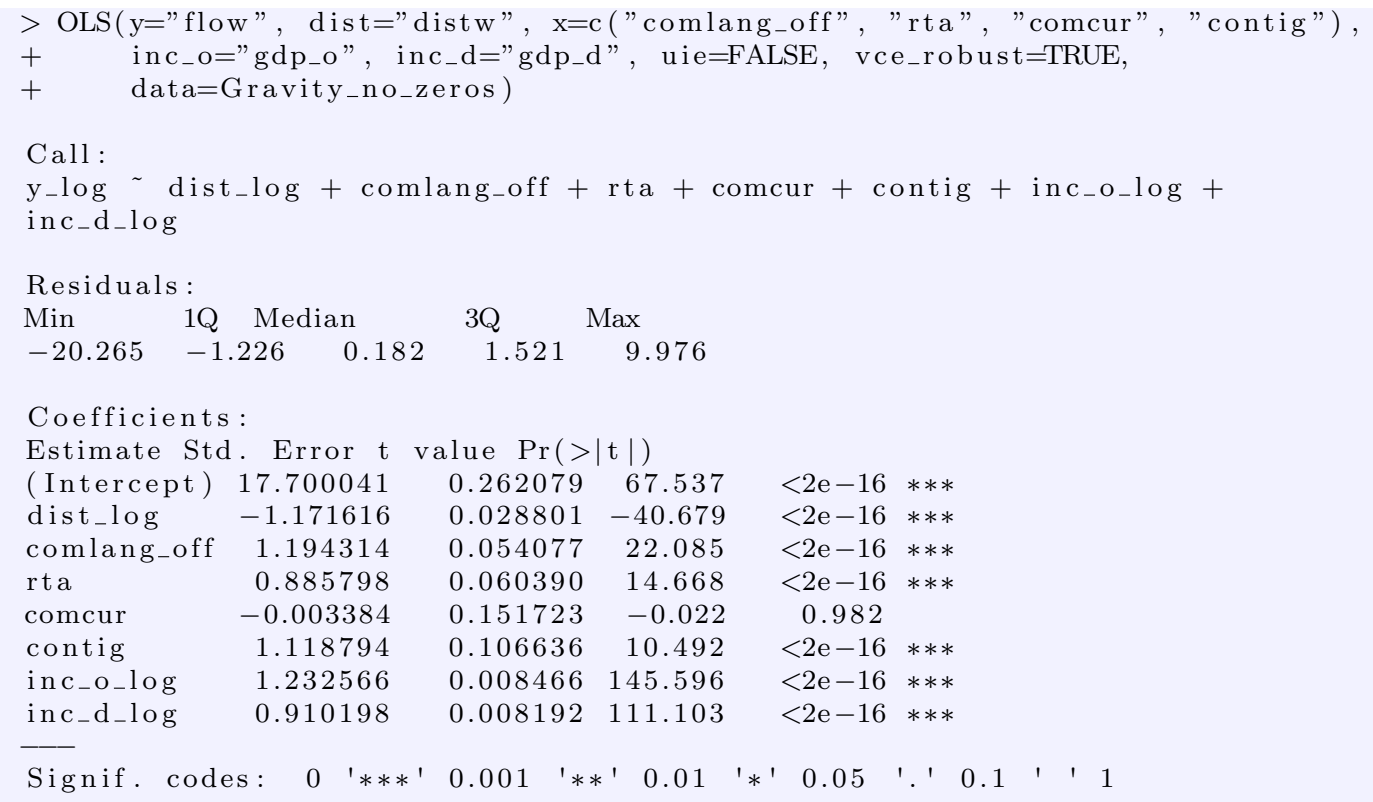


Residual standard error: 2.451 on 17080 degrees of freedom Multiple R-squared: 0.6461 , Adjusted R-squared: 0.646 F-statistic: 4875 on 7 and 17080 DF, p-value: $<2.2 \mathrm{e}-16$

\subsection{Fixed effects}

To account for MR terms, Feenstra (2002) and Feenstra (2004) propose to use importer and exporter fixed effects. Due to these effects, all unilateral influences such as GDPs can no longer be estimated. A disadvantage of the use of fixed effects is that, when applied to panel data, the number of country-year or country-pair fixed effects can be computationally too high for estimation. In addition, no comparative statics are possible with fixed effects as the MR terms are not estimated explicitly. Nevertheless, Head and Mayer (2014) highlight the importance of the use of fixed effects. Country specific fixed effects are considered by incorporating "iso_o" and "iso_d" in fe (see Table 5) next to other possible bilateral variables. When applying the function Fixed_Effects to panel data, country-pair fixed effects or interaction effects with the time variable may be applied, but the function and especially the inclusion of distance as an independent variable may have to be changed depending on the effects used. See Section 1's part on panel data for further information. The function Fixed_Effects estimates gravity models in their additive form.

Table 5: Additional variables for Fixed_Effects

\begin{tabular}{ll}
\hline Variable & Usage \\
\hline $\mathrm{fe}$ & vector of names (type: character) of fixed effects. The default is set to \\
& the unilateral identifiers "iso_o" and "iso_d" for cross-sectional data. \\
& When using panel data, interaction terms of the iso-codes and time may \\
& be added in either fe or x.
\end{tabular}

An example of how to apply the function Fixed_Effects to an example dataset in gravity and the resulting output is shown in the following:

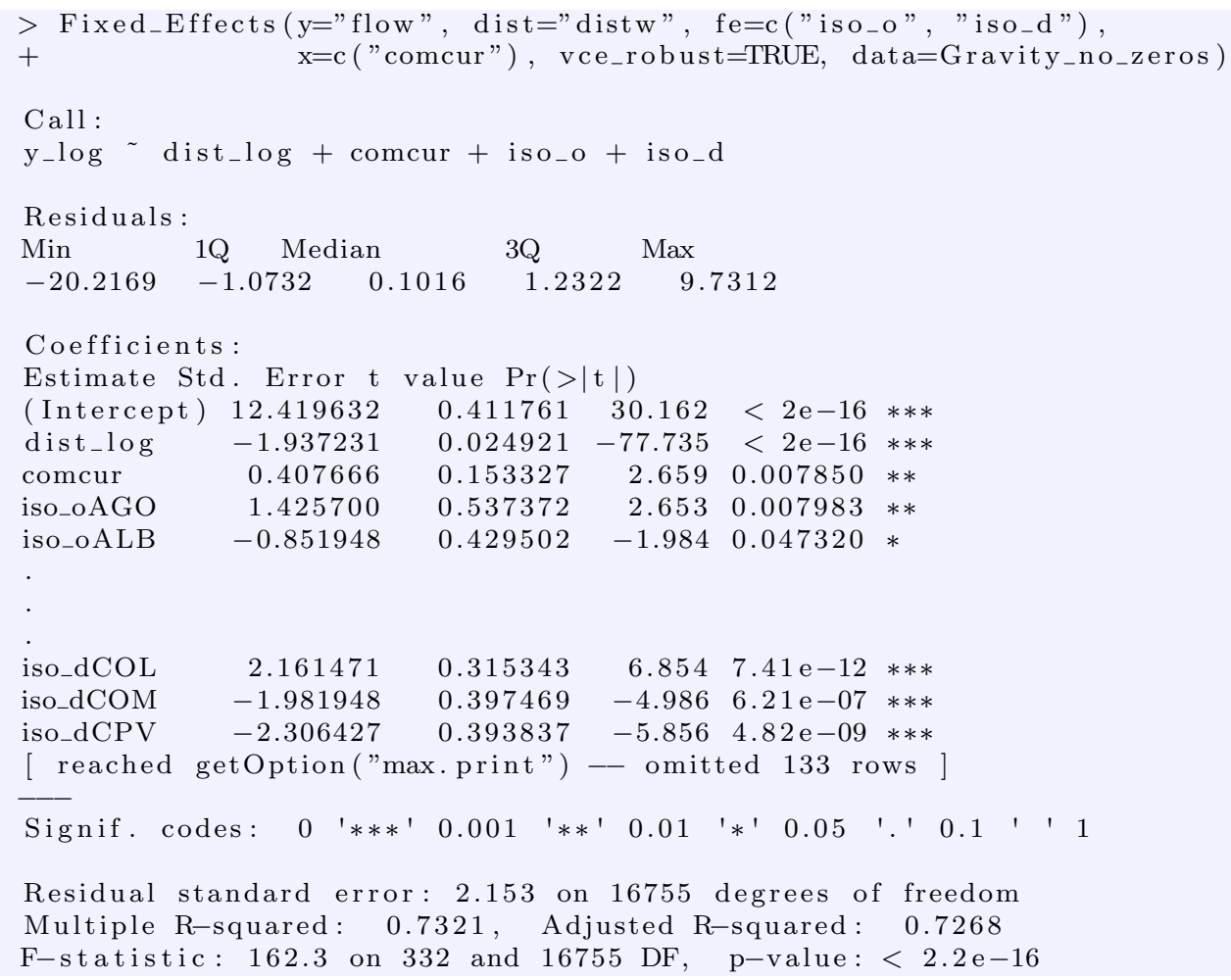




\subsection{Double demeaning (DDM)}

A further method to estimate gravity models in their additive form is the usage of Double Demeaning, DDM, as introduced by Head and Mayer (2014). By subtracting importer and exporter averages on the left and right hand side of the respective gravity equation, all unilateral influences including the MR terms vanish. Therefore, no unilateral variables may be added as independent variables for the estimation. The function DDM first logs the dependent variable and the distance variable. Afterwards, the dependent and independent variables are transformed in the following way (exemplary shown for trade flows, $X_{i j}$ ):

$$
\begin{array}{r}
\left(\log X_{i j}\right) \cdot D D M=\left(\log X_{i j}\right)-\left(\log X_{i j}\right) \cdot \text { origin.mean } \\
\quad-\left(\log X_{i j}\right) \cdot \text { destination.mean }+\left(\log X_{i j}\right) . \text { mean } .
\end{array}
$$

One subtracts the mean value for the origin country and the mean value for the destination country and adds the overall mean value to the logged trade flows. This procedure is repeated for all dependent and independent variables. The transformed variables are then used for the estimation. DDM is easily applied, but, as shown in Head and Mayer (2014), very sensitive to missing data.

An example of how to apply the function DDM to an example dataset in gravity and the resulting output is shown in the following:

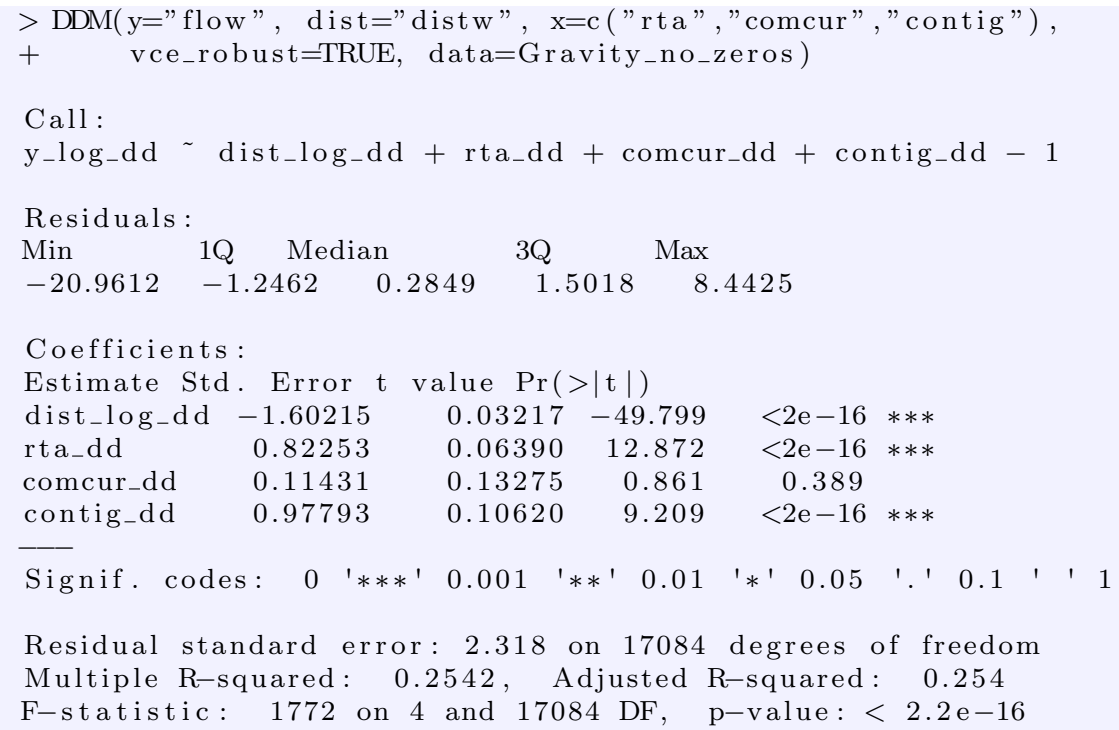

\subsection{Bonus vetus OLS (BVU, BVW)}

Baier and Bergstrand (2009) and Baier and Bergstrand (2010) argue that on the one hand, the non-linear least squares (NLS) approach in Anderson and van Wincoop (2003) is in line with the theory and capable of conducting comparative statics, but on the other hand is too computationally costly and complex and therefore received little attention in the literature. On the other hand, fixed effects estimation, while incorporating MR terms and being easily set up, does not allow for comparative statics. Therefore, Baier and Bergstrand (2010) suggest a modification of the simple OLS that is easily implemented, allows for comparative statics and yields results close to those of NLS, called Bonus vetus OLS (BVU and BVW). They estimate gravity models in their additive form. For the theoretical foundation of their estimation method see Anderson and van Wincoop (2003) and Anderson and van Wincoop (2004). As unilateral income elasticities are assumed, flows are divided by the product of unilateral incomes. The dependent variable for the estimation is therefore $\log \left(y /\left(i n c_{o} * i n c_{d}\right)\right)$. By applying a Taylor-series expansion and the assumption of symmetrical, bilateral trade costs, they develop a reduced gravity model in which multilateral and worldwide resistance enter exogenously. Baier and Bergstrand (2010) distinguish two types of Bonus vetus estimations depending on how the Taylor-series is centered. One method, called BVU, uses simple averages 
while the other, called BVW, uses GDP weights. Depending on which method is used, the transaction costs are weighted differently. For advantages and disadvantages of both methods see Baier and Bergstrand (2009) and Baier and Bergstrand (2010).

To give an example with simple averages (BVU), distance would be transformed to Multilateral and World Resistance, MWR, of distance in the following way:

$$
M W R . D_{i j}=\frac{1}{N}\left(\sum_{i=1}^{N} \log D_{i j}\right)+\frac{1}{N}\left(\sum_{j=1}^{N} \log D_{i j}\right)-\frac{1}{N^{2}}\left(\sum_{i=1}^{N} \sum_{j=1}^{N} \log D_{i j}\right)
$$

with $D_{i j}$ denoting the bilateral distance, $N$ the number of countries and $M W R . D_{i j}$ the transformed variable adjusted for multilateral resistances.

When using BVW, the simple averages are replaced by GDP weights. The transformed variables are included as independent variables in the estimation. The resulting equation can be estimated by simple OLS. For an application of a method close to Bonus vetus on panel data, see Kareem et al. (2016).

An example of how to apply the functions BVU and BVW to an example dataset in gravity and the resulting output is shown in the following:

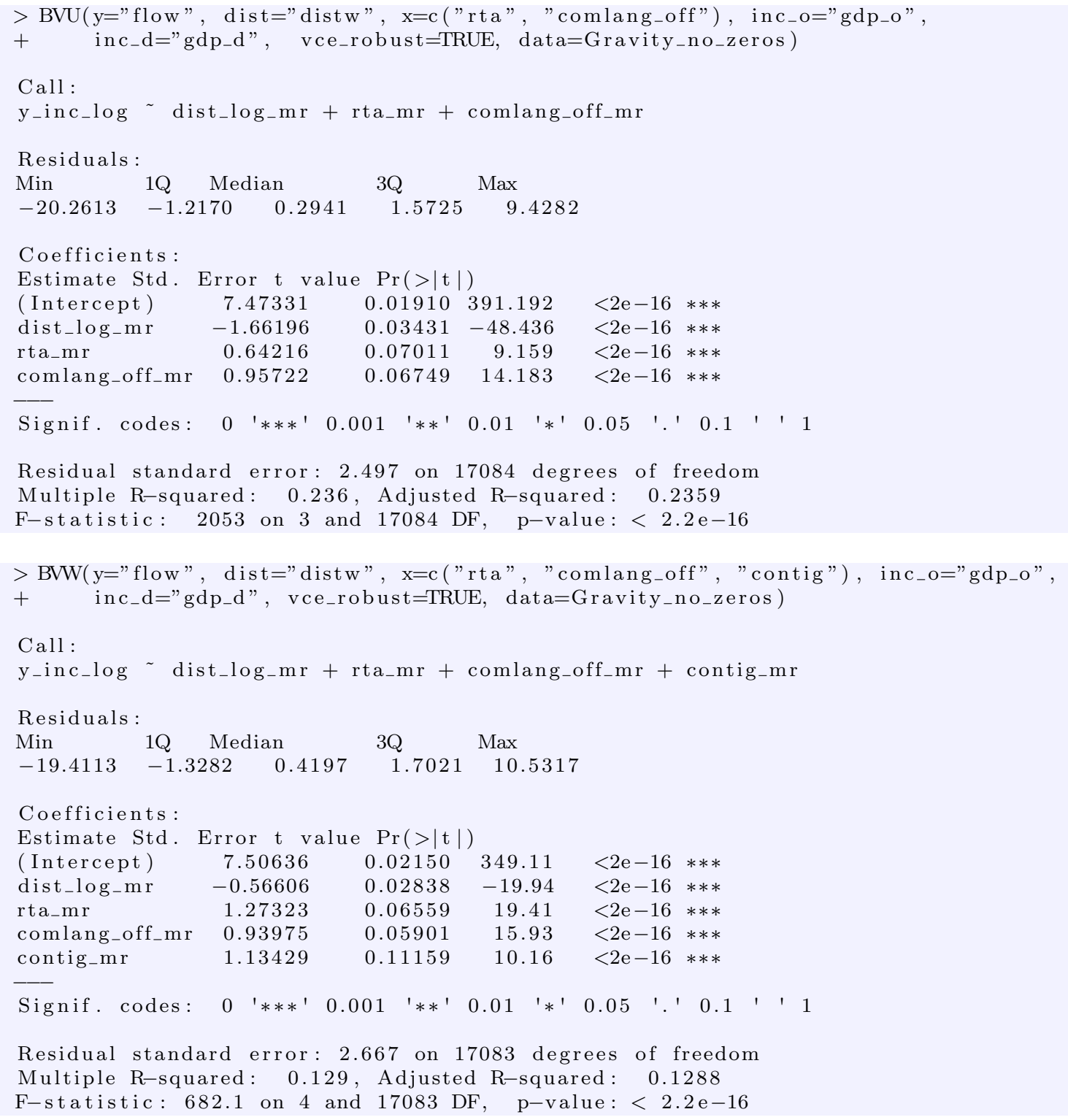




\subsection{Structural iterated least squares (SILS)}

The function SILS, structural iterated least squares, aims at estimating the MR terms (6) and (7) explicitly. The procedure was introduced by Anderson and van Wincoop (2003) using non-linear least squares and adapted by Head and Mayer (2014). See Egger and Staub (2016) for a comparison of iterative estimation methods and fixed effects methods. The function utilizes the dependencies between the MR terms and the transaction costs. The transaction costs influence the transactions between two countries in a direct and an indirect way by their effect on the MR terms. It estimates gravity equations in their additive form. SILS performs the following steps (Head and Mayer 2014):

- The unknown terms $\Pi_{i}$ and $P_{j}$ are initially set equal to 0 .

- The particular gravity equation is estimated in its additive form via OLS to obtain estimates for the parameters determining the transaction costs. The dependent variable for the estimation equals $\log \left(X_{i j} /\left(Y_{i} * Y_{j} * \Pi_{i} * P_{j}\right)\right)$.

- Given the newly estimated parameters, a contraction mapping algorithm is used to update $\Pi_{i}$ and $P_{j}$.

- These steps are repeated until the estimated parameters stop changing significantly.

Table 6 contains the additional variables for the function SILS. They are used to restrict the maximum iterations in the inner and outer loop of SILS as well as the stopping rule. Compared to the other estimation methods, SILS can be very time consuming. When using it, the updated coefficients for every iteration are shown. When the iteration stops, summary statistics for the last iteration are shown.

Table 6: Additional variables for SILS

\begin{tabular}{ll}
\hline Variable & Usage \\
\hline maxloop & maximum number of iterations. The default is set to 50. \\
maxloop2 & maximum number of inner loop iterations. The default is set to 50. \\
dec_places & number of decimal precision. The default is set to 4. \\
verbose & verbose (type: logic) determines whether the estimated coefficients of \\
& each iteration should be printed in the console. The default is set to \\
& FALSE.
\end{tabular}

An example of how to apply the function SILS to an example dataset in gravity and the resulting output is shown in the following:

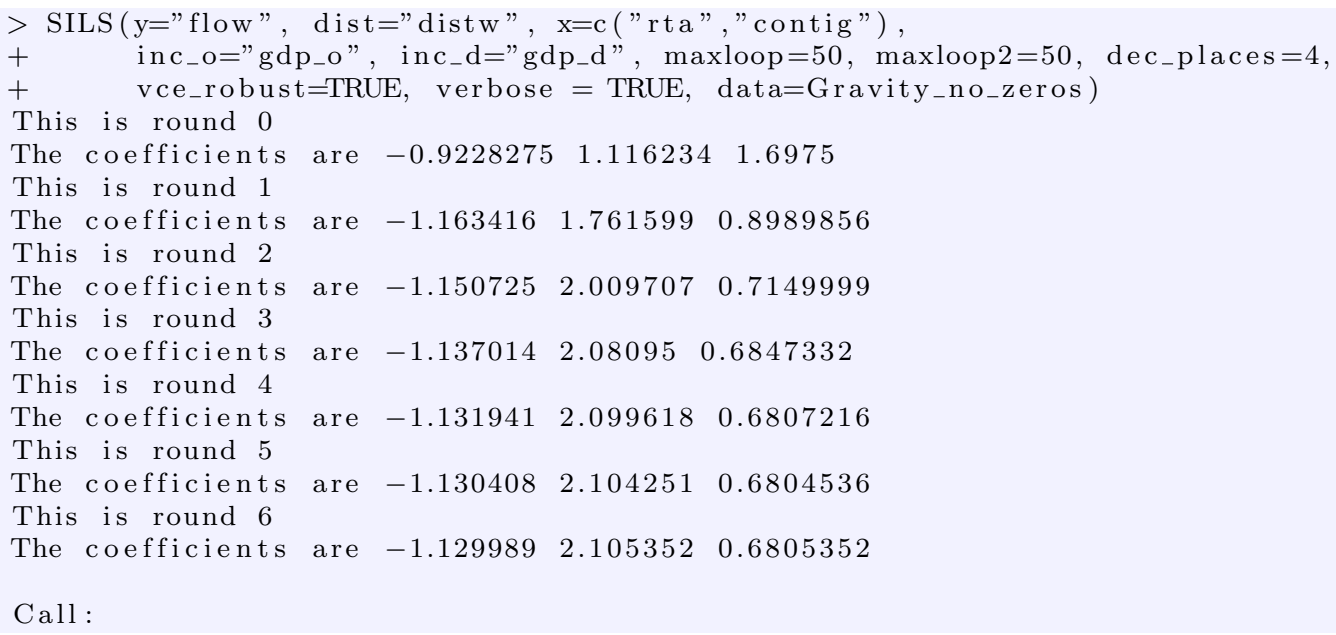




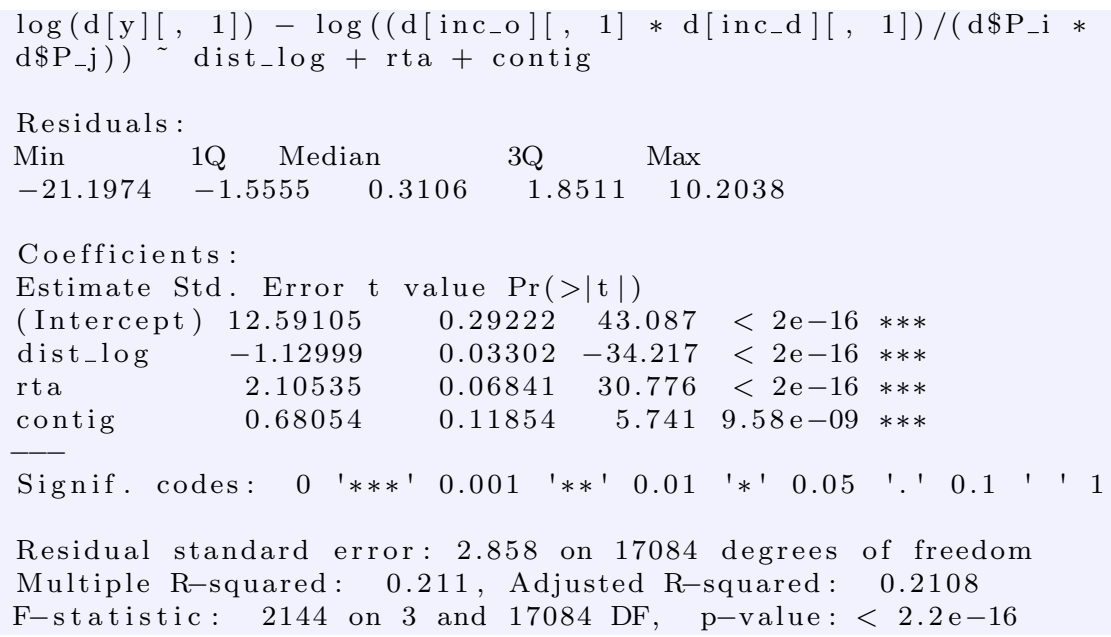

\subsection{Tetrads}

In order to use the fixed effects method with panel data, a huge number of dummy variables has to be included into the estimation. Thus, estimating these models can lead to significant computational difficulties. Head et al. (2010) present Tetrads as an estimation method circumventing this problem. They exploit the multiplicative form of the gravity equation to form the ratio of ratios. In doing so, both MR terms drop out of the equation. Table 7 shows the additional arguments for the function Tetrads.

Table 7: Additional variables for Tetrads

\begin{tabular}{ll}
\hline Variable & Usage \\
\hline $\mathrm{k}$ & reference importing country, default is set to "USA". \\
$\mathrm{l}$ & reference exporting country, default is set to "JPN". \\
multiway_vcov & (type: logic) optional; determines whether a function implementing the \\
& multi-way clustering of variance-covariance matrices of Cameron, Gel- \\
& bach, and Miller (2011) in the package multiway_vcov is used for the \\
& estimation. In case multiway_vcov=TRUE, the cluster.vcov function is \\
& used. The default value is set to TRUE. \\
\hline
\end{tabular}

A reference importer and a reference exporter have to be chosen. Preferably, these reference countries should have very few (if any) zero trade flows. The default importing country $k$ is the United States, while the default exporting country 1 is Japan. Only those exporters trading with the reference importer and importers trading with the reference exporter will be included in the estimation. Tetrads can be used for both, cross-sectional and panel data. Here, the notation for panel data as shown in Head et al. (2010) is used.

The two ratios $(\mathrm{R})$ are calculated as:

$$
R_{i\{j k\} t}=\frac{X_{i j t}}{X_{i k t}}=\frac{\left(Y_{j t} / P_{j t}\right) t_{i j t}}{\left(Y_{k t} / P_{k t}\right) t_{i k t}}
$$

and

$$
R_{l\{j k\} t}=\frac{X_{l j t}}{X_{l k t}}=\frac{\left(Y_{j t} / P_{j t}\right) t_{l j t}}{\left(Y_{k t} / P_{k t}\right) t_{l k t}}
$$

In a second step, the ratio of ratios is computed as:

$$
r_{\{i l\}\{j k\} t}=\frac{R_{i\{j k\} t}}{R_{l\{j k\} t}}=\frac{X_{i j t} / X_{i k t}}{X_{l j t} / X_{l k t}}=\frac{t_{i j t} / t_{i k t}}{t_{l j t} / t_{l k t}} .
$$


The equation is then estimated in its additive form. To account for a possible correlation between the error terms, a three-way-clustering - it, $j t$, and $i j$ - can be applied using the method of Cameron et al. (2011) with multiwayvcov=TRUE. Due to the transformation of data, it is not possible to estimate the influences of unilateral effects. If Tetrads is used for panel data, the user has to exclude time-invariant effects, such as geographical distance.

An example of how to apply the function Tetrads to an example dataset in gravity and the resulting output is shown in the following:

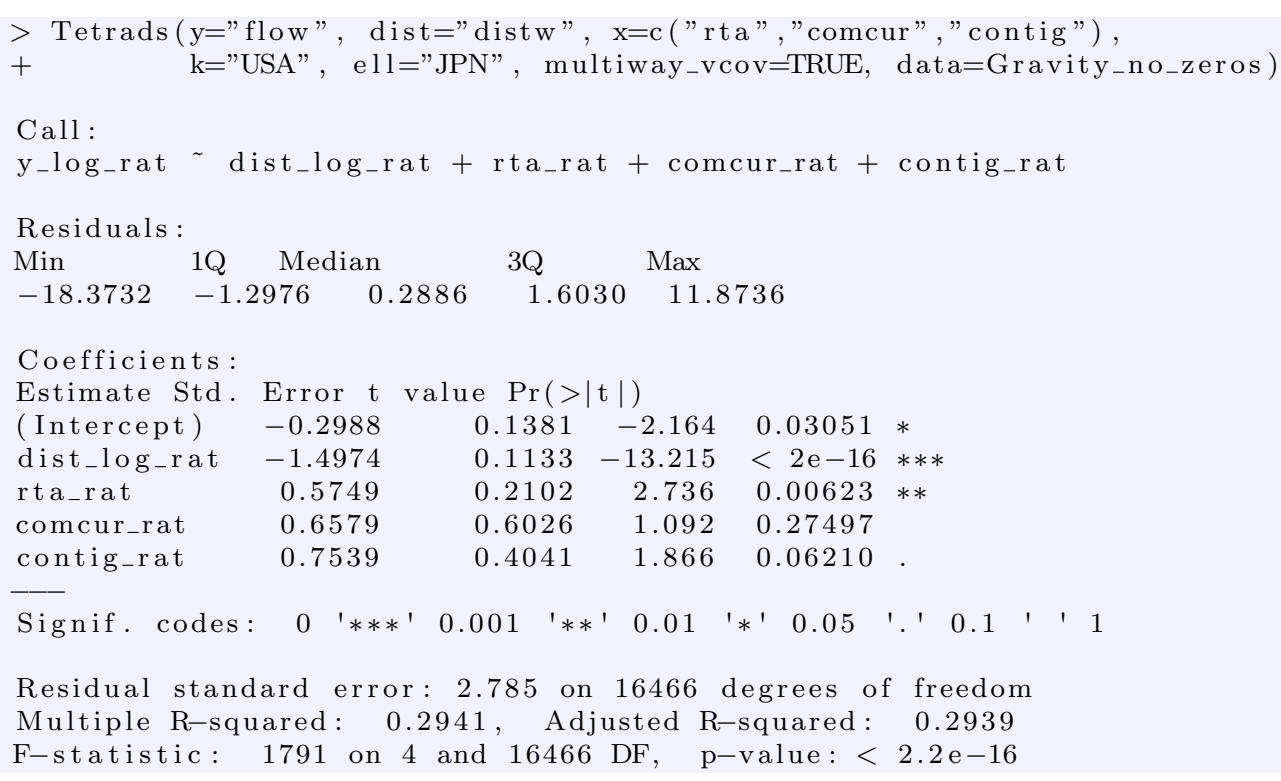

\subsection{Tobit}

In many cases, data values underlie natural boundaries. Tobin (1958) analyzes how to properly model this kind of data where on the one hand a substantial amount of observations equals the boundary value and on the other hand the observations exceeding the boundary do so to a large extend. As an example, he uses household expenditures and the Engel curve. As a binary regression model would be suitable for modeling whether an observation equals or exceeds the boundary and linear regression would be suitable for those values exceeding the boundary, the two approaches are combined in a so called Tobit model. In a Tobit model where the dependent variable is bounded by 0 , a latent variable $y_{i}^{*}$ is modeled and the observed values of the dependent variable $y_{i}$ are assumed to either equal this variable when they exceed threshold 0 or 0 elsewise, see (14). The model is therefore also known as censored regression model.

$$
y_{i}= \begin{cases}y_{i}^{*} & \text { if } y_{i}^{*}>0 \\ 0 & \text { else }\end{cases}
$$

Tobit models exist in various forms with possible upper or lower boundaries, which not necessarily equal 0 . As a combination of a binary and linear regression is modeled, the interpretation of the estimated coefficients has to take this into account. Therefore, as stated in e.g. Baldwin and Nino (2006), the marginal effects of an explanatory variable on the expected value of the dependent variable, i.e. the estimated coefficient, equals the product of both the probability of the latent variable exceeding the threshold and the marginal effect of the explanatory variable on the expected value of the latent variable. As gravity datasets for trade flows often contain a great number of values equal to zero, the Tobit approach can be suitable for this kind of data, especially if zeros arise from rounding small trade volumes. This approach of adding an arbitrary constant to the data is criticized, e.g. by Head and Mayer (2014). They argue that an underlying economic theory is missing and the estimates are volatile with respect to the choice of the constant. For more information about Tobit models in the context of gravity models for trade, see e.g. Kareem et al. (2016). 
The Tobit function implemented in the package gravity represents a left-censored Tobit model with a censoring threshold assumed to be known. In order to provide users with the possibility to set the threshold to a certain number, the function comes with the argument added_constant described in Table 8 .

Table 8: Additional variables for Tobit

\begin{tabular}{ll}
\hline Variable & Usage \\
\hline added_constant & scalar (type: numeric); represents the constant to be added to the de- \\
& pendent variable. The default value is 1. The minimum of $\log (y+$ \\
& added_constant) is taken as the left boundary in the Tobit model. In \\
& the often used case of added_constant $=1$, the dependent variable is left \\
& censored at value 0 as $\log (1)=0$.
\end{tabular}

An example of how to apply the function Tobit to an example dataset in gravity and the resulting output is shown in the following:

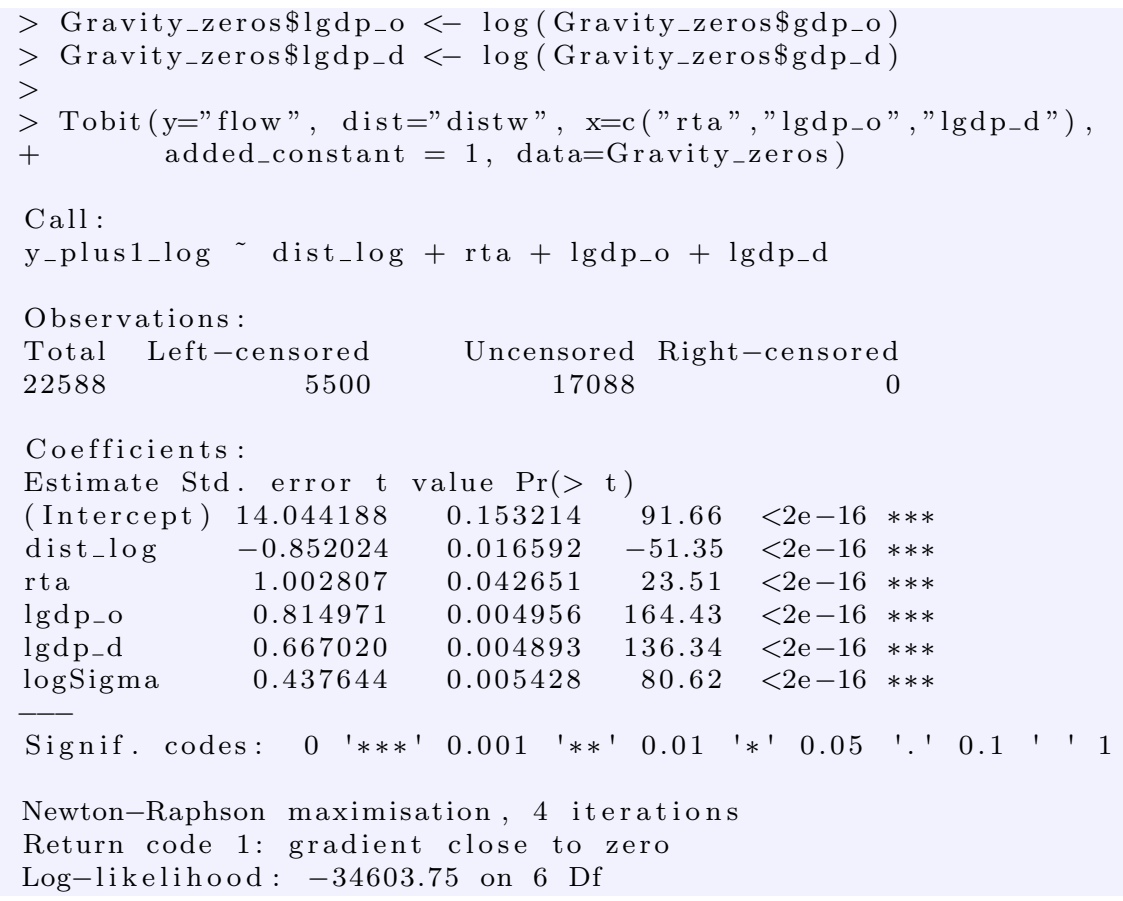

\subsection{ET-Tobit}

The main critic of the Tobit model described in Section 4.8 is that the censoring value is arbitrarily chosen and this choice can have a great influence on the parameter estimates. In contrast to that approach, in the Eaton and Tamura (1994) Tobit model, also called threshold Tobit model, the censoring value or threshold is assumed to be unknown and therefore has to be estimated from the data. It is for example used in Martin and Pham (2015) and Santos Silva and Tenreyro (2011). Compared to the usual ET-Tobit approaches, in this package, the estimation of this threshold is done before the other parameters are estimated. We follow the approach in Carson and Sun (2007), who show that taking the minimum positive flow value as an estimate of the threshold is super-consistent and that using this threshold estimate ensures that the parameter maximum likelihood estimates are asymptotically normal with the asymptotic variance identical to the variance achieved when the threshold is known. Hence, in the function ET_Tobit first the threshold is estimated as the minimum positive flow. This threshold is added to the flow variable. It is logged afterwards and taken as the dependent variable in a left-censored regression with the left boundary equal to the smallest logged value. Even though this approach is more elaborate than the Tobit approach with an 
arbitrarily set threshold, Head and Mayer (2014) criticize it for a lacking compelling structural interpretation. Furthermore, in their study Santos Silva and Tenreyro (2011) find very large bias for ET-Tobit.

An example of how to apply the function ET_Tobit to an example dataset in gravity and the resulting output is shown in the following:

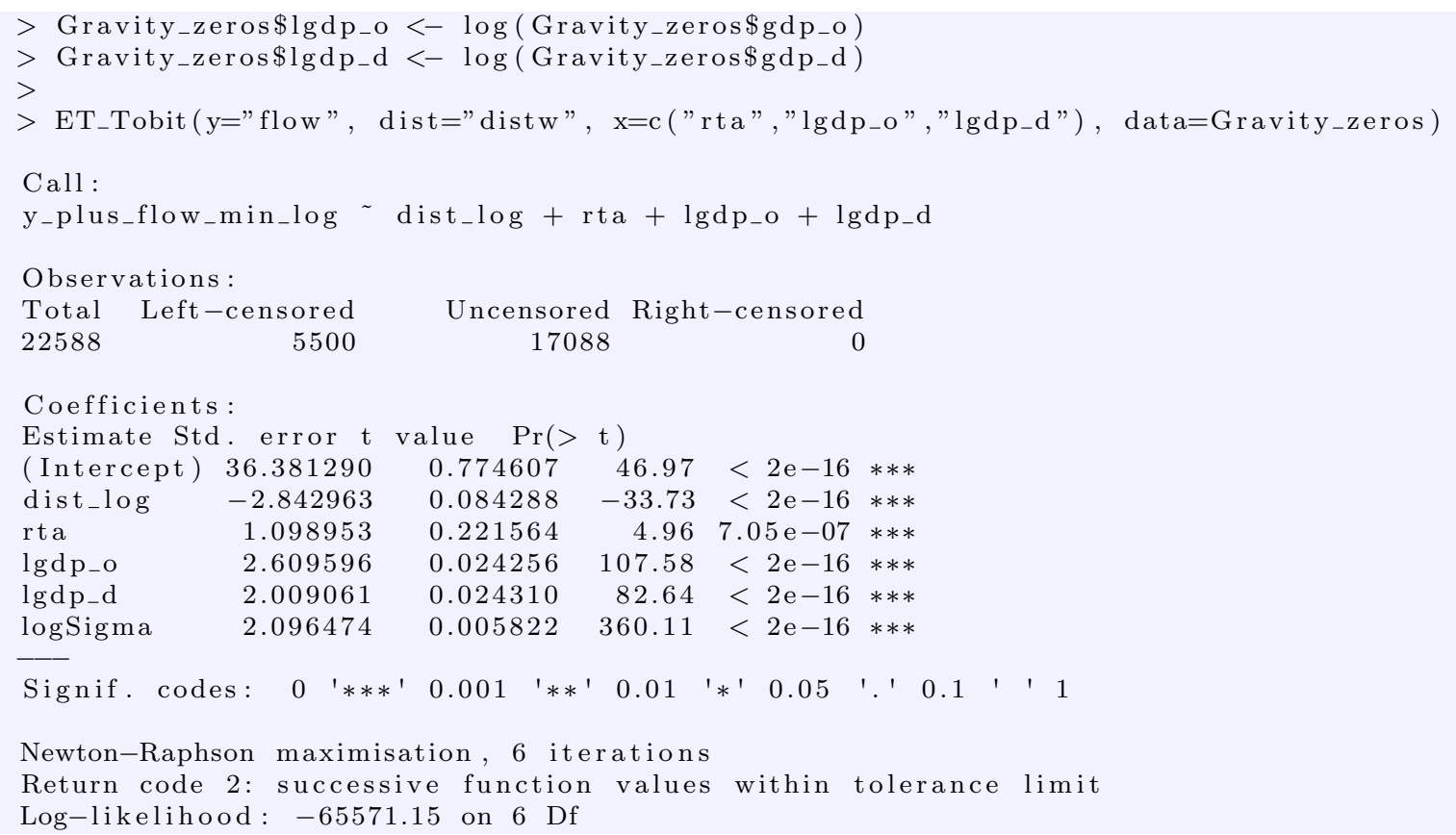

\subsection{EK-Tobit}

In addition to the two Tobit approaches presented in Section 4.8 and 4.9, the Eaton and Kortum (2001) Tobit approach utilizes import country specific censoring values. Compared to ET-Tobit, instead of taking the minimum positive flow as an estimate of the threshold for all countries, for each importing country the minimum positive threshold is taken as an estimate of its country specific threshold. Using the function EK_Tobit, all values of the dependent variable are redefined as intervals. The positive observations have both interval bounds equal to their original value. For zero flows the interval is left open. The right border of the interval is set to the log of the minimum positive trade flow of the respective importing country. The transformed data is then used in an interval regression with observation specific boundaries. Head and Mayer (2014) highlight this method in comparison to the other two Tobit approaches due to its applicability and interpretability.

An example of how to apply the function EK_Tobit to an example dataset in gravity and the resulting output is shown in the following:

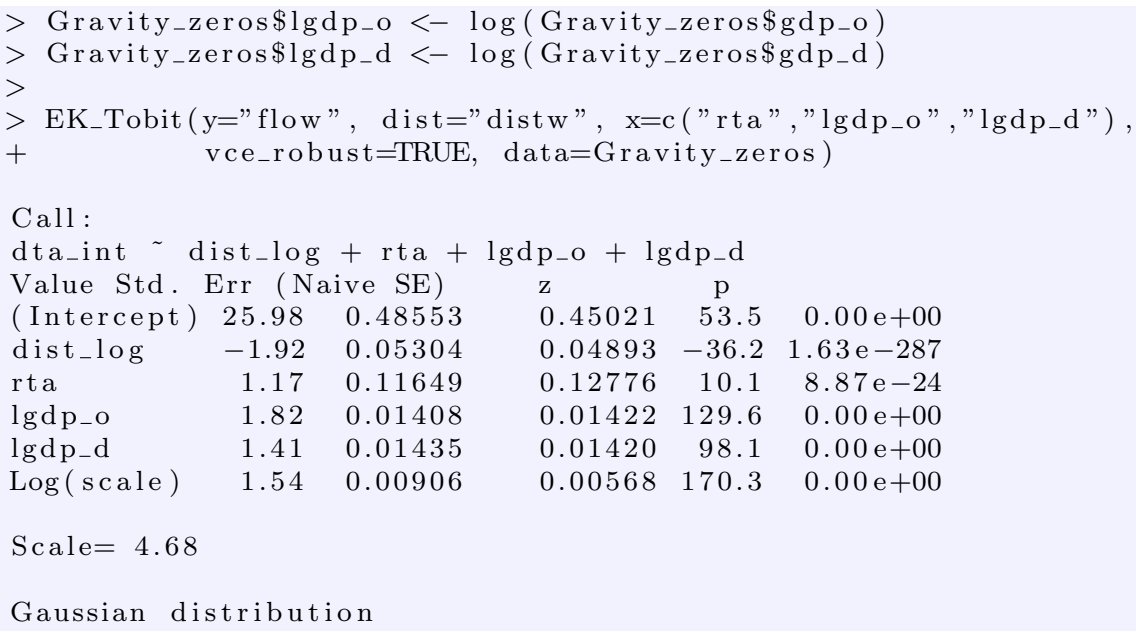




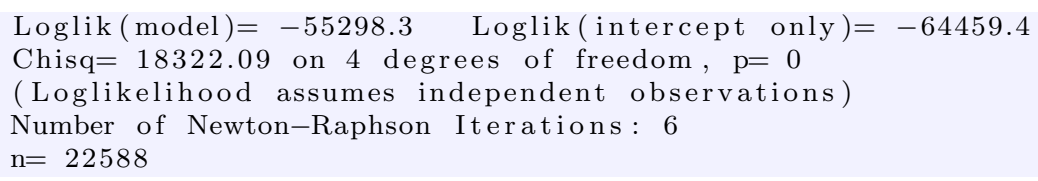

\subsection{Poisson pseudo maximum likelihood (PPML)}

Poisson Pseudo Maximum Likelihood, PPML, is recommended in the influential paper of Santos-Silva and Tenreyro (2006). They argue that estimating gravity equations in their additive form by OLS leads to inconsistency in the presence of heteroscedasticity. Due to Jensen's inequality $E(\log Y) \neq \log E(Y)$, Santos-Silva and Tenreyro (2006) advise researchers to estimate gravity models in their multiplicative form. Furthermore, as trade flows are not logged, one major drawback of many other estimation methods diminishes, namely the handling of trade flows equal to zero. They can remain in the dataset. Following Santos-Silva and Tenreyro (2006), heteroscedasticity likely occurs in trade data, with $0 \leq X_{i j}$, as the variance $\operatorname{var}\left(X_{i j}\right)$ is decreasing the closer trade flows are to zero. On the other hand, the greater the trade flows become, the higher the variance becomes as well. In order to utilize the pseudo ML estimates, the option vce_robust=TRUE by default in analogy to the vce(robust) in Stata. When choosing PPML the Poisson family is used with log-link. Similar methods utilizing the log-link, but different underlying distributions are Gamma PML (GPML), Negative Binomial PML (NBPML), and Nonlinear Least Squares (NLS), see Section 4.12, 4.13, and 4.14. See Manning and Mullahy (2001) or Gómez-Herrera (2013) who compare the performance of these methods under different data generating processes and their usage in the literature. Under consideration of zeros and heteroscedasticity, Santos-Silva and Tenreyro (2006) argue that the PPML estimator would be preferable over GPML or NLS. See also Santos Silva and Tenreyro (2011) for an extension of their simulation study in Santos-Silva and Tenreyro (2006). Martin and Pham (2015) tests the PPML estimator among others under different economically-based data generating processes, also with a focus on heterogenous data containing many zero values, and also finds it to have a good performance. For extensions of PPML, see for example Burger et al. (2009).

In order to illustrate all estimation methods using the same example dataset, the function PPML is also applied to data restricted to positive trade flows even though it would allow trade flows to be zero. An exemplary output is shown in the following:

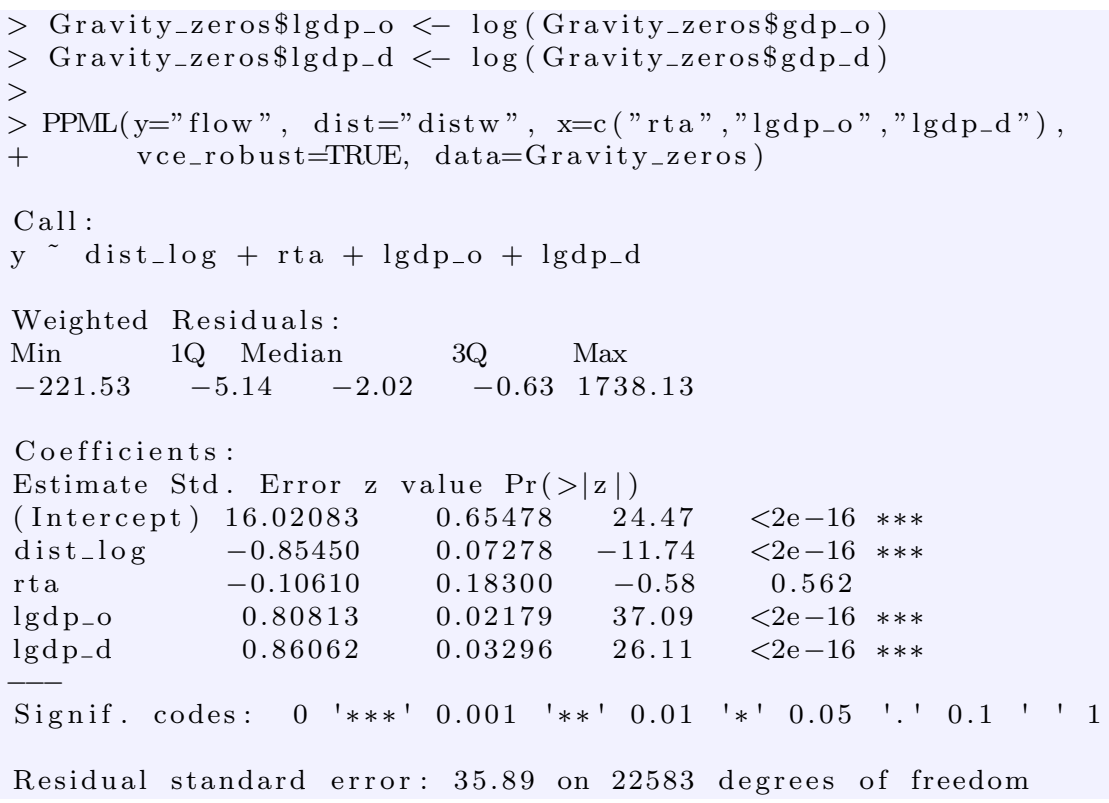




\subsection{Gamma pseudo maximum likelihood (GPML)}

For the main description of the kind of estimation method used for Gamma Pseudo Maximum Likelihood, GPML, see Section 4.11. The estimation method is similar to PPML, but utilizes the gamma instead of the poisson distribution, thereby implies different assumptions to the data structure and does not allow for zero trade values. Even though Santos-Silva and Tenreyro (2006) argue in favor of PPML instead of GPML, especially in case of heteroscedasticity, Head and Mayer (2014) highlight that depending on data structure there exist cases where GPML is preferable to PPML.

An example of how to apply the function GPML to an example dataset in gravity and the resulting output is shown in the following:

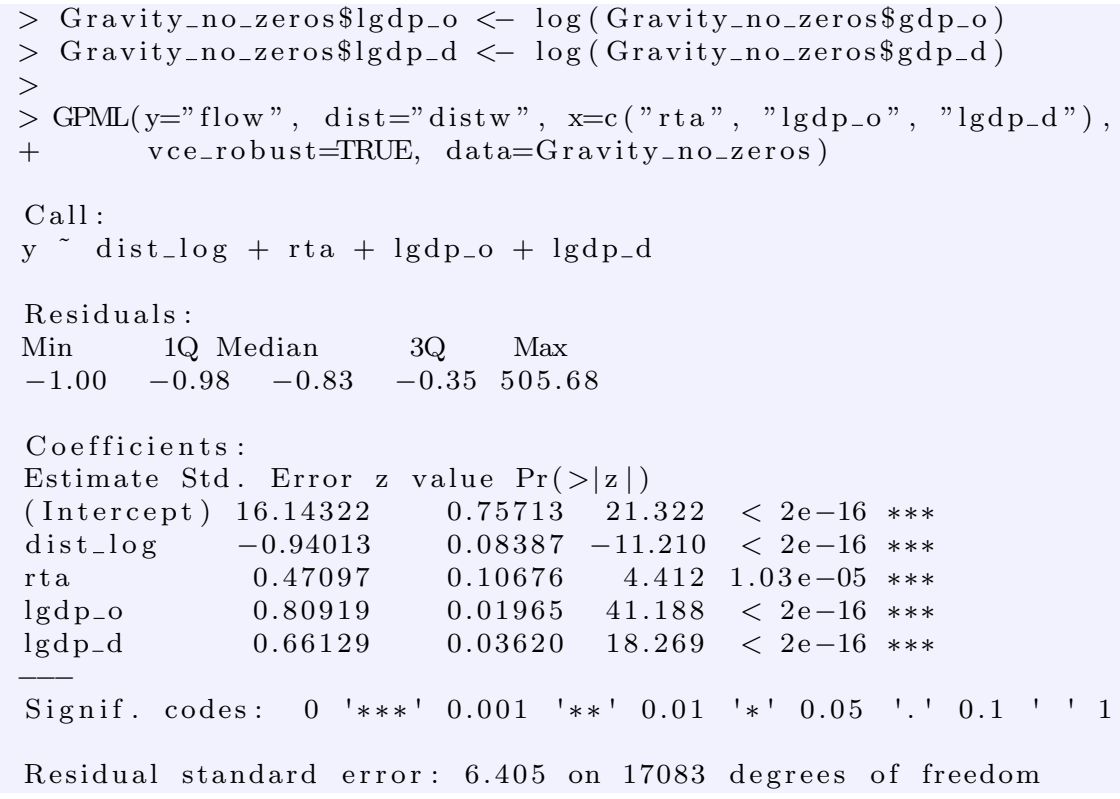

\subsection{Negative binomial pseudo maximum likelihood (NBPML)}

For the main description of the kind of estimation method used for Negative Binomial Pseudo Maximum Likelihood, NBPML, see Section 4.11. The estimation method is similar to PPML, but utilizes the negative binomial instead of the poisson distribution and thereby implies different assumptions to the data structure. It also allows for zero values in the dependent variable. See e.g. De Benedictis and Taglioni (2011) for an application of this method and Head and Mayer (2014) for critics.

In order to illustrate all estimation methods using the same example dataset, the function NBPML is also applied to data restricted to positive trade flows even though it would allow trade flows to be zero. An exemplary output is shown in the following:

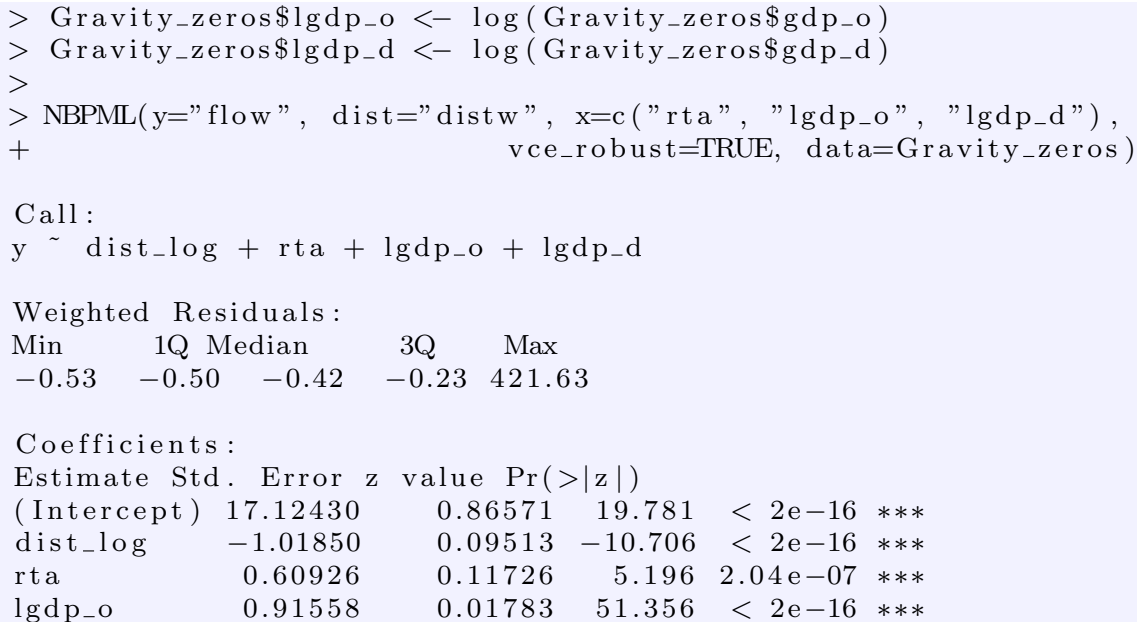




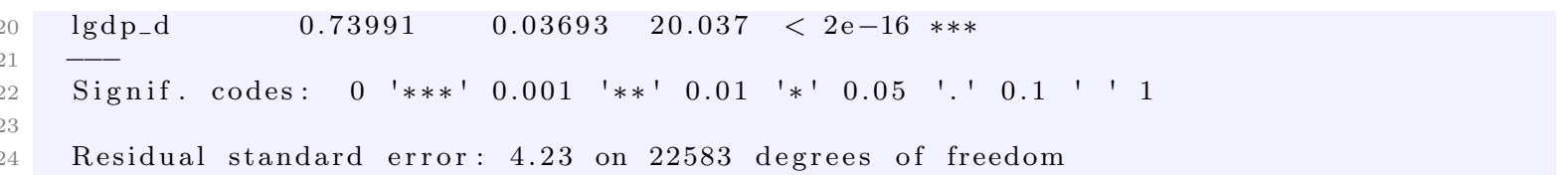

\subsection{Nonlinear least squares (NLS)}

For the main description of the kind of estimation method used for Nonlinear Least Squares, NLS, see Section 4.11. The estimation method is similar to PPML, but utilizes the negative binomial instead of the poisson distribution and thereby implies different assumptions to the data structure. It also allows for zero values in the dependent variable. As the method may not lead to convergence when poor starting values are used, the output of the PPML function is used for the starting values. For a comparison of different types of NLS to other methods, see e.g. Martin and Pham (2015) or Manning and Mullahy (2001). For critics see e.g. Head and Mayer (2014).

In order to illustrate all estimation methods using the same example dataset, the function NLS is also applied to data restricted to positive trade flows even though it would allow trade flows to be zero. An exemplary output is shown in the following:

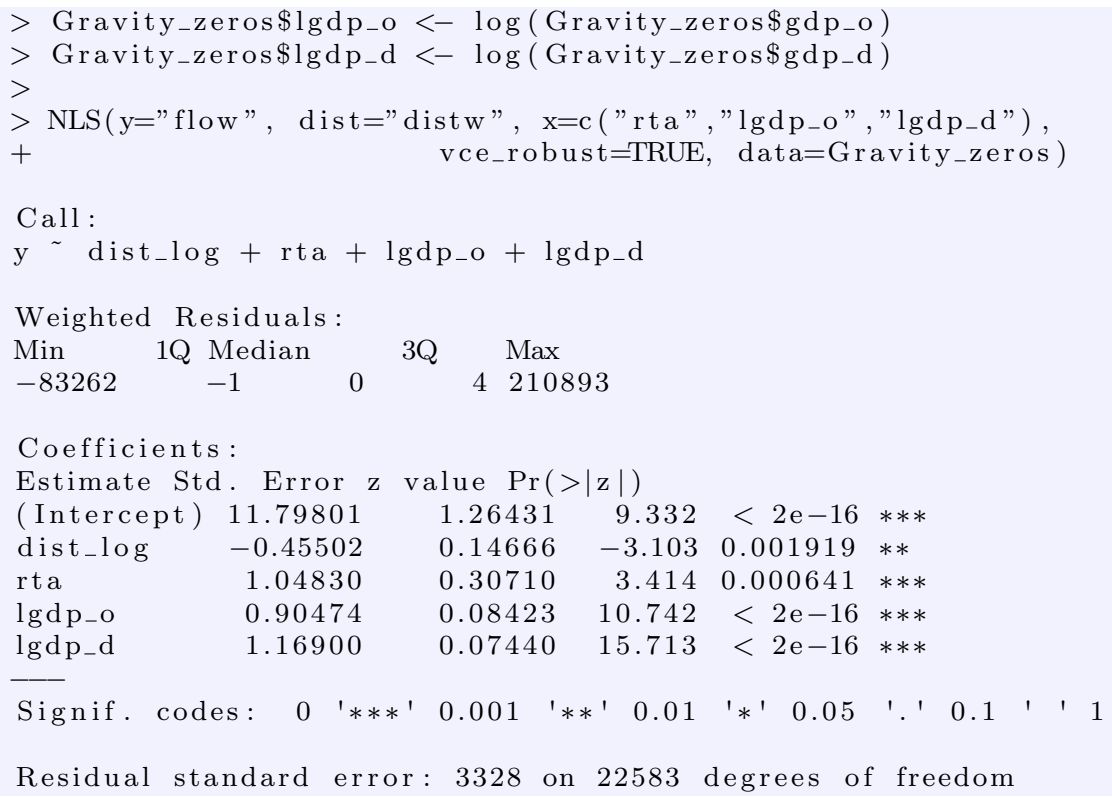

\section{Conclusion}

As Head and Mayer (2014) or Martínez-Zarzoso (2013) point out there is no best estimation method for gravity models. Depending on the dataset at hand, the research question as well as robustness checks, it is up to the researcher to decide which method(s) to use. As especially for gravity beginners it is difficult to get an overview of the different possible estimation methods as well as to implement the methods in $\mathrm{R}$, the package gravity provides a wrapper of different standard estimation methods for gravity models. Next to the more complicated methods DDM, BVU, BVW, SILC, Tetrads, and EK-Tobit which were programmed to lead identical results to the Stata code provided on Gravity Cookbook website ${ }^{4}$ by Keith Head and Thierry Mayer, other common estimation methods for gravity models are added, namely OLS, Fixed Effects, PPML, GPML, NBPML, NLS, ET-Tobit, and Tobit. By considering the descriptions and codes of the estimation methods, users can get a comprehensive and application-oriented overview of the different methods, see which method may be suitable for certain research questions or type of data, and extend the code available in order to fit

\footnotetext{
${ }^{4}$ https://sites.google.com/site/hiegravity/
} 
their research projects. Furthermore, users can directly apply all methods to the example datasets Gravity_no_zeros or Gravity_zeros. For more advanced gravity models, e.g. the use of panel data, see the literature referred to in sections 1 and 2. Future work is to expand the functions to the needs of panel data, i.e. implementing grouped fixed effects as shown in Guimarães and Portugal (2009) in order to circumvent high dimensional fixed effects in large scale longitudinal applications. Contributions, extensions and error corrections are very welcome. Please do not hesitate to contact us.

\section{References}

Anderson JE (1979). "A Theoretical Foundation for the Gravity Equation." American Economic Review, 69(1), 106-16.

Anderson JE (2010). "The Incidence of Gravity." In The Gravity Model in International Trade: Advances and Applications, chapter 3, pp. 71-87. Cambridge University Press, Cambridge.

Anderson JE (2011). "The Gravity Model." Annual Review of Economics, 3(1), 133-160. doi:10.3386/w16576.

Anderson JE, van Wincoop E (2003). "Gravity with Gravitas: A Solution to the Border Puzzle." American Economic Review, 93(1), 170-192.

Anderson JE, van Wincoop E (2004). "Trade Costs." Journal of Economic Literature, 42(3), $691-751$.

Baier SL, Bergstrand JH (2009). "Bonus Vetus OLS: A Simple Method for Approximating International Trade-Cost Effects Using the Gravity Equation." Journal of International Economics, 77(1), 77-85.

Baier SL, Bergstrand JH (2010). "Approximating General Equilibrium Impacts of Trade Liberalizations Using the Gravity Equation: Applications to NAFTA and the European Economic Area." In van Bergeijk, PAG and Brakman, S (ed.), The Gravity Model in International Trade: Advances and Applications, chapter 4, pp. 88-134. Cambridge University Press, Cambridge.

Baldwin R (2007). "Trade Effects of the Euro: A Comparison of Estimators." Journal of Economic Integration, 22, 780-818.

Baldwin RE, Nino VD (2006). "Euros and Zeros: The Common Currency Effect on Trade in New Goods." Technical Report 12673, National Bureau of Economic Research, Inc. URL http://www. nber.org/papers/w12673.

Bergeijk PAGv, Brakman S (2010). "Introduction: The Comeback of the Gravity Model." In van Bergeijk, PAG and Brakman, S (ed.), The Gravity Model in International Trade: Advances and Applications, chapter 1, pp. 1-26. Cambridge University Press, Cambridge.

Burger M, Van Oort F, Linders GJ (2009). "On the Specification of the Gravity Model of Trade: Zeros, Excess Zeros and Zero-Inflated Estimation." Spatial Economic Analysis, 4(2), $167-190$.

Cameron AC, Gelbach JB, Miller DL (2011). "Robust Inference with Multiway Clustering." Journal of Business 83 Economic Statistics, 2, 238-249.

Carson RT, Sun Y (2007). "The Tobit Model with a Non-Zero Threshold." The Econometrics Journal, 10(3), 488-502. 
De Benedictis L, Taglioni D (2011). "The Gravity Model in International Trade." In L De Benedictis, L Salvatici (eds.), The Trade Impact of European Union Preferential Policies, pp. 55-89. Springer.

Eaton J, Kortum S (2001). "Trade in Capital Goods." European Economic Review, 45(7), $1195-1235$.

Eaton J, Tamura A (1994). "Bilateralism and Regionalism in Japanese and US Trade and Direct Foreign Investment Patterns." Journal of the Japanese and international economies, 8(4), 478-510.

Egger P, Pfaffermayr M (2003). "The Proper Panel Econometric Specification of the Gravity Equation: A Three-Way Model with Bilateral Interaction Effects." Empirical Economics, 28(3), 571-580.

Egger PH, Staub KE (2016). "GLM Estimation of Trade Gravity Models with Fixed Effects." Empirical Economics, 50(1), 137-175.

Feenstra RC (2002). "Border Effects and the Gravity Equation: Consistent Methods for Estimation." Scottish Journal of Political Economy, 49(5), 491-506.

Feenstra RC (2004). Advanced International Trade - Theory and Evidence, volume 1. Princeton University Press, Princeton, New Jersey.

Gómez-Herrera E (2013). "Comparing Alternative Methods to Estimate Gravity Models of Bilateral Trade." Empirical Economics, 44(3), 1087-1111.

Guimarães P, Portugal P (2009). "A Simple Feasible Alternative Procedure to Estimate Models with High-Dimensional Fixed Effects." IZA discussion papers, (3935). URL http: //nbn-resolving.de/urn:nbn:de:101:1-2009020957.

Head K, Mayer T (2014). "Chapter 3 - Gravity Equations: Workhorse, Toolkit, and Cookbook." In Gita Gopinath, Elhanan Helpman and Kenneth Rogoff (ed.), Handbook of International Economics, volume 4 of Handbook of International Economics, pp. 131 - 195. Elsevier.

Head K, Mayer T, Ries J (2010). "The Erosion of Colonial Trade Linkages After Independence." Journal of International Economics, 81(1), 1-14.

Kareem FO, Martinez-Zarzoso I, Brümmer B (2016). "Fitting the Gravity Model when Zero Trade Flows are Frequent: A Comparison of Estimation Techniques using Africa's Trade Data." GlobalFood Discussion Papers, 77. URL http://hdl.handle.net/10419/126396.

Leibrecht M, Riedl A (2014). "Modelling FDI Based on a Spatially Augmented Gravity Model: Evidence for Central and Eastern European Countries." The Journal of International Trade \& Economic Development, 23(8), 1206-1237.

Linders GJ, De Groot HLF (2006). "Estimation of the Gravity Equation in the Presence of Zero Flows." Tinbergen Institute Discussion Paper, 072(3). URL https://papers. tinbergen.nl/06072.pdf.

Manning WG (1998). "The Logged Dependent Variable, Heteroscedasticity, and the Retransformation Problem." Journal of Health Economics, 17(3), 283-295.

Manning WG, Mullahy J (2001). "Estimating Log Models: To Transform or not to Transform?" Journal of Health Economics, 20(4), 461-494.

Martin W, Pham CS (2015). "Estimating the Gravity Model When Zero Trade Flows Are Frequent and Economically Determined." Technical Report WPS7308, World Bank. URL http://documents. worldbank. org/curated/en/695631467998785933/pdf/WPS7308. pdf. 
Martínez-Zarzoso I (2013). "The Log of Gravity Revisited." Applied Economics, 45(3), 311327.

Martínez-Zarzoso I, Nowak-Lehmann D F, Vollmer S (2007). "The Log of Gravity Revisited." Center for European, Governance and Economic Development Research Discussion Papers 64, University of Goettingen, Department of Economics.

Mayer T, Zignago S (2011). "Notes on CEPII's Distances Measures: The GeoDist database." Working Papers 2011-25, CEPII research center. URL http://www.cepii.fr/CEPII/en/ publications/wp/abstract. asp?NoDoc=3877.

Metulini R, Patuelli R, Griffith DA (2016). "A Spatial-Filtering Zero-Inflated Approach to the Estimation of the Gravity Model of Trade." Quaderni - Working Paper DSE, 1081. URL http://dx.doi.org/10.6092/unibo/amsacta/5426.

Möhlmann LJ, Ederveen S, de Groot HLF, Linders GJM (2010). "Intangible Barriers to International Trade: A Sectoral Approach." In Peter A G van Bergeijk and Steven Brakman (ed.), The Gravity Model in International Trade - Advances and Applications, chapter 8, pp. 224-251. Cambridge University Press.

Newton I (1729). The Mathematical Principles of Natural Philosophy. By Sir Isaac Newton. Translated into English by Andrew Motte. To Which are Added, The Laws of the Moon's Motion, According to Gravity. By John Machin Astron. Prof. Gresh. and Secr. R. Soc. In two volumes. Benjamin Motte, at the Middle-Temple-Gate, in Fleetstreet.

Orlova D, Jost T (2006). "Zur Erklärung der Zuwanderungen nach Deutschland: Ein Gravitationsmodell." Arbeitspapiere des Instituts für Statistik und Ökonometrie 36, Johannes Gutenberg-Universität Mainz, Institut für Statistik und Ökonometrie.

Ravenstein EG (1889). "The Laws of Migration." Journal of the Royal Statistical Society, LII, 241-301.

Santos-Silva JMC, Tenreyro S (2006). "The Log of Gravity." The Review of Economics and Statistics, 88(4), 641-658.

Santos Silva JMC, Tenreyro S (2011). "Further Simulation Evidence on the Performance of the Poisson Pseudo-Maximum Likelihood Estimator." Economics Letters, 112(2), 220-222.

Tinbergen J (1962). Shaping the World Economy - Suggestions for an International Economic Policy. Twentieth Century Fund, New York.

Tobin J (1958). "Estimation of Relationships for Limited Dependent Variables." Econometrica, 26(1), 24-36. ISSN 00129682, 14680262. doi:10.2307/1907382. URL http://www.jstor. org/stable/1907382.

Wang J (2011). "Wavelet-Based Traffic Matrix Modeling." Thesis at the Department of Electrical- \& Computer Engineering McGill University, Montreal, Canada. 


\section{Affiliation:}

Jan Pablo Burgard

Department of Economic- and Social Statistics

Trier University

54286 Trier, Germany

E-mail: burgardj@uni-trier.de

\section{Austrian Journal of Statistics}

published by the Austrian Society of Statistics

Volume 47

June 2018 http://www.ajs.or.at/

http://www.osg.or.at/

Submitted: 2017-03-24

Accepted: 2017-12-20 